\title{
Milk-soluble formula increases food intake and reduces $/ / 6$ expression in elderly rat hypothalami
}

\author{
Hassina Ould Hamouda ${ }^{1,2}$, Bernadette Delplanque ${ }^{1,2}$, Yacir Benomar,2, \\ Delphine Crépin $^{1,2}$, Laure Riffault ${ }^{1,2}$, Pascale LeRuyet ${ }^{3}$, Cécile Bonhomme ${ }^{4}$ \\ and Mohammed Taouis ${ }^{1,2}$ \\ ${ }^{1}$ Neuroendocrinologie Moléculaire de la Prise Alimentaire, University of Paris-Sud, UMR 8195, \\ F-91405 Orsay, France \\ ${ }^{2}$ Neuroendocrinologie Moléculaire de la Prise Alimentaire, CNRS, Centre de Neurosciences Paris-Sud, UMR 8195, \\ F-91405 Orsay, France \\ ${ }^{3}$ Service Nutrition, Lactalis Recherche et Développement, 8 Fromy, CS 60082, 35240 Retiers, France \\ ${ }^{4}$ Lactalis Nutrition Parc d'Activité de Torcé-secteur Est, 35370 Torcé, France
}

\begin{abstract}
Malnutrition in the elderly is accompanied by several metabolic dysfunctions, especially alterations in energy homeostasis regulation and a loss of insulin responsiveness. Nutritional recommendations aim to enrich food with high protein and energy supplements, and protein composition and lipid quality have been widely studied. Despite the numerous studies that have examined attempts to overcome malnutrition in the elderly through such nutritional supplementation, it is still necessary to study the effects of a combination of protein, lipids, and vitamin D (VitD). This can be done in animal models of elderly malnutrition. In the present study, we investigated the effects of several diet formulae on insulin responsiveness, inflammation, and the hypothalamic expression of key genes that are involved in energy homeostasis control. To mimic elderly malnutrition in humans, elderly Wistar rats were food restricted $(R,-50 \%)$ for 12 weeks and then refed for 4 weeks with one of four different isocaloric diets: a control diet; a diet where milk soluble protein (MSP) replaced casein; a blend of milk fat, rapeseed, and DHA (MRD); or a full formula (FF) diet that combined MSP and a blend of MRD (FF). All of the refeeding diets contained VitD. We concluded that: i) food restriction led to the upregulation of insulin receptor in liver and adipose tissue accompanied by increased Tnf $\alpha$ in the hypothalamus; ii) in all of the refed groups, refeeding led to similar body weight gain during the refeeding period; and iii) refeeding with MSP and MRD diets induced higher food intake on the fourth week of refeeding, and this increase was associated with reduced hypothalamic interleukin 6 expression.
\end{abstract}

\section{Correspondence}

should be addressed

to M Taouis

Email

mohammed.taouis@u-psud.fr

\section{Introduction}

Malnutrition in older adults may be attributed to several factors, including decreased food intake (Nieuwenhuizena et al. 2010) and reduced energy expenditure resulting from a sedentary lifestyle. Moreover, malnutrition in elderly
Key Words
- aging
- inflammation
- insulin responsiveness
- milk fat
milk protein 
(Foster et al. 2010). Paradoxically, aging has been also associated with anorexia, which results in the diminution of body weight and in cachexia (Rolland et al. 2011, Biolo et al. 2014). Thus, aging is characterized by an alteration in energy homeostasis control and an inability to respond to physiological needs. Indeed, in elderly rats, the loss of appetite has been shown to be associated with the downregulation of the expression of hypothalamic neuropeptide $\mathrm{Y}(\mathrm{N} p y)$, an orexigenic neuropeptide, but not with changes in the expression of $\alpha M s h$ or Cart, which are anorexigenic neuropeptides (Sohn et al. 2002, Wolden-Hanson et al. 2004). These changes in Npy can most probably be attributed to alterations in both leptin and insulin hypothalamic signaling. In addition to the brain, aging progressively impairs the most metabolically active tissues, such as liver, adipose tissue, and muscle, and this impairment leads to numerous defects at the molecular and cellular levels. Insulin resistance is one of the most common features of aging-associated malnutrition and metabolic disorders (Escrivá et al. 2007). Importantly, insulin resistance has also been shown to be a risk factor for cognitive decline and neurodegenerative diseases, such as Alzheimer's disease in the elderly (Paz-Filho et al. 2008, Cardoso et al. 2009). Thus, promoting overall insulin sensitivity in elderly subjects could contribute to a delay in the onset of some agingrelated disorders, including eating disorders, inflammation, and cognitive decline. This could be achieved through nutritional intervention. Adapting protein and lipid quality and amounts to an elderly diet is one nutritional manipulation that could improve wholebody insulin sensitivity, energy homeostasis control, and inflammatory status (Akinkuoliea et al. 2011, Panza et al. 2011, Volpi et al. 2013). Indeed, supplementing the diet with fish oil polyunsaturated (n-3) fatty acids has been shown to improve insulin sensitivity and to reduce proinflammatory factors, such as interleukin 6 (IL6) (Taouis et al. 2002, Cancelas et al. 2007, Chung et al. 2009, Li et al. 2014). Aging is also characterized by a reduction in muscle protein and by slow muscle protein synthesis. Consequently, efforts have been made to improve diet protein composition in order to increase the accretion of muscle proteins and to slow sarcopenia (Guillet et al. 2004, Paddon-Jones et al. 2004, Katsanos et al. 2005, Hirabara et al. 2013). Different protein supplementations have been tested in elderly subjects. Interestingly, whey proteins resulted in higher muscle protein synthesis as compared with soy proteins (Philips et al. 2009). This has been attributed to the fact that soy proteins are more preferentially directed toward splanchnic synthesis than whey proteins are (Tang \& Phillips 2009). In addition, the improvement of insulin action in muscle is crucial for maintaining a positive balance between protein synthesis and degradation as well as for slowing down sarcopenia and frailty syndrome (Fulop et al. 2010). Despite the tremendous number of studies that have examined attempts to overcome malnutrition in the elderly by adapting the diet through nutritional supplementations (Dangin et al. 2003, Nestel et al. 2014), it is still necessary to study the effects of a combination of protein, lipids, and micronutrients (such as vitamin $\mathrm{D}(\mathrm{VitD}))$. This can be achieved in animal models (such as elderly rodents) of undernutrition in elderly humans. Although the results obtained using such models cannot be directly extrapolated to elderly humans, they could highlight some directions for future research.

In the present study, we used new nutritional combinations that consisted of milk lipids and protein in association with polyunsaturated (n-3) fatty acid in the presence of VitD, and we investigated the effects of these combinations on elderly undernourished rats. To our knowledge, the present study is the first to combine both milk lipids and protein in elderly rats. Indeed, despite its high saturated fatty acid content, milk fat has been reported to improve insulin sensitivity (Holmberg \& Thelin 2013) and to reduce central obesity (German et al. 2009). Furthermore, there is no consistent association between the consumption of milk fat and an increase in cardiovascular risks (Le Ruyet \& Le Goer 2010). The second nutrient that we tested was milk protein that consisted of native whey protein prepared by the microfiltration of skim milk. This processing fully maintained the nutritional and functional capacities of milk protein, as previously reported (Pfeifer et al. 2009). Following food restriction, animals were refed with different nutritional combinations for 4 weeks. We compared a control diet (CD, a soy oil/casein semi-synthetic diet that was equivalent to chow diet) with diets where milk soluble protein (MSP) replaced casein, where a blend of milk fat, rapeseed, and DHA (MRD) replaced soy oil, or a full formula (FF) combination of the MSP and MRD diets with a specific increase in protein in the presence of high VitD concentrations.

\section{Materials and methods}

\section{Animals and experimental design}

Male Wistar rats (aged 20 months) were purchased from Janvier (Le Genest-St-Isle, France). They were housed individually in a controlled temperature

Published by Bioscientifica Ltd. 
$\left(20-22^{\circ} \mathrm{C}\right)$ and controlled humidity (around 40\%) environment with a $12 \mathrm{~h}$ light: $12 \mathrm{~h}$ darkness cycle. They had free access to water.

During the adaptation period (the first 2 weeks), all of the rats were allowed to feed ad libitum (AL) on a control semi-synthetic diet (4\% lipids from soy vegetal oil, $74 \%$ carbohydrates from sucrose and corn starch, and 14\% protein from casein, supplemented with a standard vitamin and mineral mix), following classical recommendations (Table 1). All of the diets were prepared within the Institut National de la Recherche Agronomique (INRA) facilities (Jouy-En-Josas, France).

A control group was allowed to feed AL for 3 months on a diet that was similar to the adaptation-period diet (AL group, $n=18$ ); these rats had a daily spontaneous intake of $24.5 \pm 0.8 \mathrm{~g} /$ day. A dietary restriction program was applied to the other animals and maintained for 3 months with an intake that was $50 \%$ of the AL diet ( $12 \mathrm{~g} / \mathrm{day}$, of the same composition, given every morning; Fig. 1). The duration of food restriction was chosen on the basis of results described in previous reports (Osowska et al. 2006, Morley 2010). At the end of the diet-restriction period, the rats were separated: one group was killed and studied as a food-restricted group (R group, $n=18$ ), and the others were separated into four groups ( $n=18$ /group) for refeeding studies. These four groups were assessed in order to compare the effects of refeeding diets that differed in terms of their protein quality or content, lipid quality, and VitD levels had on the restoration of different physiological and biochemical parameters (Table 2). Rats continued to be housed individually so that food intake could be measured. All of the refeeding diets were isocaloric and enriched in lipid as compared to the AL (6\% versus $4 \%$ ) at the expense of sucrose (26\% versus $28 \%$ ).

The CD group was refed with the $\mathrm{CD}$, which contained $14 \%$ casein as source of protein and $6 \%$ soy oil as a source of lipids, and $1 \mathrm{IU} / \mathrm{g}$ VitD. The MSP group was refed with a similar diet to that of the CD group, except that casein was replaced by MSP (Prolacta, Lactalis Ingredients, Bourgbarre, France). The diet contained the same amounts of lipid (6\% soy oil) and VitD (1 IU/g). The MRD group was refed with a similar diet as the $\mathrm{CD}$ group in terms of protein quantity and quality (14\% casein) and VitD, but the soy oil was replaced with a $6 \%$ blend of milk fat and rapeseed (50:50) supplemented with $0.072 \mathrm{~g}$ of DHA (longchain omega-3). The FF group was refed with a FF that contained increased levels of MSP (22\% versus 14\%) at the expense of sucrose (18\% versus $26 \%$ ), a $6 \%$ blend of milk fat and rapeseed (50:50) supplemented with $0.072 \mathrm{~g}$ of DHA, and $5 \mathrm{IU} / \mathrm{g}$ VitD (instead of $1 \mathrm{IU} / \mathrm{g}$ ) (Table 1). The decision to add VitD was based on the crucial role it plays in preserving muscle mass and bone density, especially in elderly people, by affecting calcium absorption and tissue incorporation (Chernoff 2005).

To avoid digestive problems, we implemented a progressive refeeding from days 1 to 5: $20 \mathrm{~g} /$ day on days $1-2,25 \mathrm{~g} /$ day on day 3 , and $30 \mathrm{~g} /$ day on day 4 ; the animals were allowed to feed AL beginning on day 5 .

All of the procedures were conducted according to the guidelines for laboratory animal care and were approved

Table 1 Composition of diets

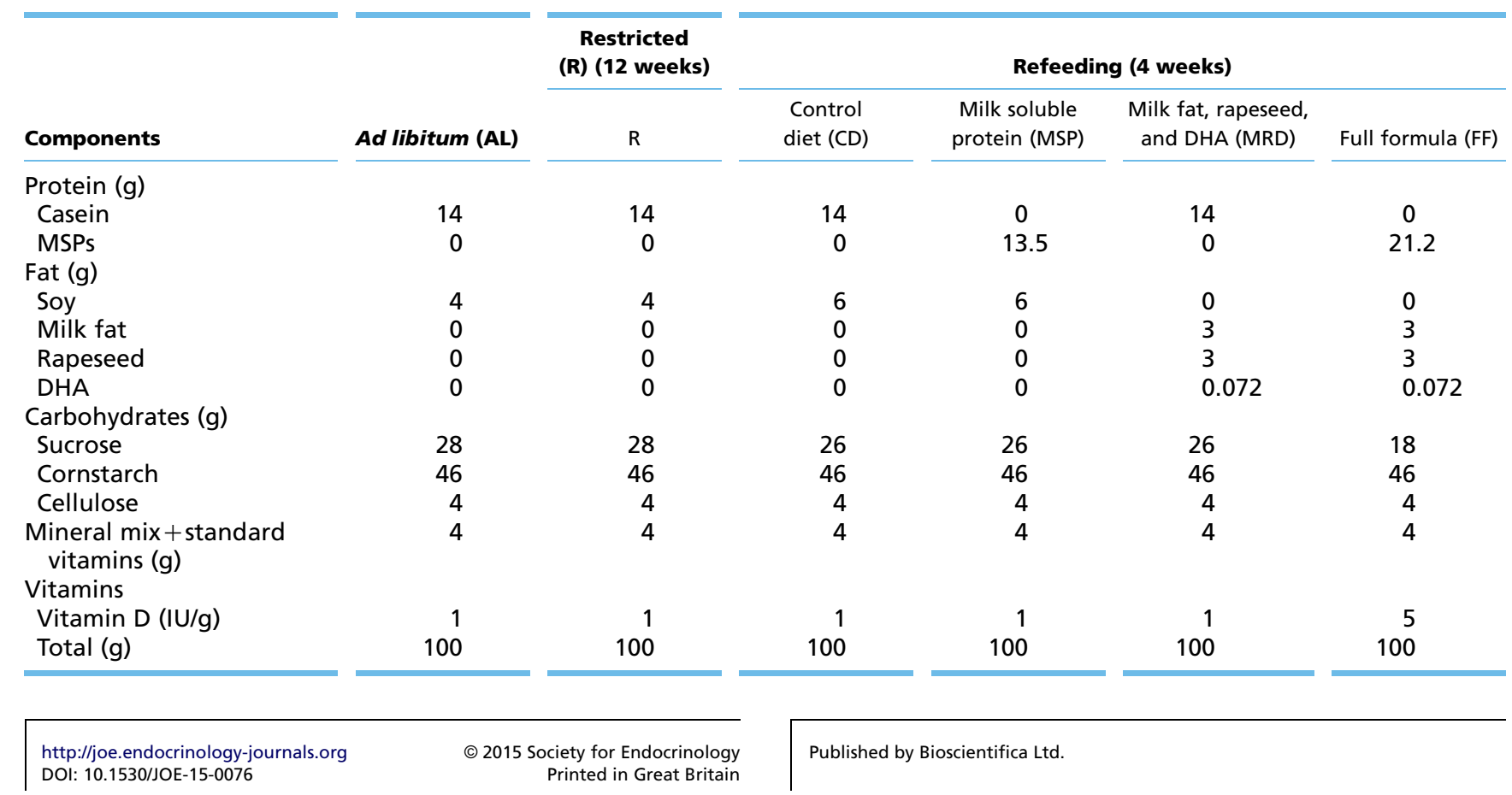




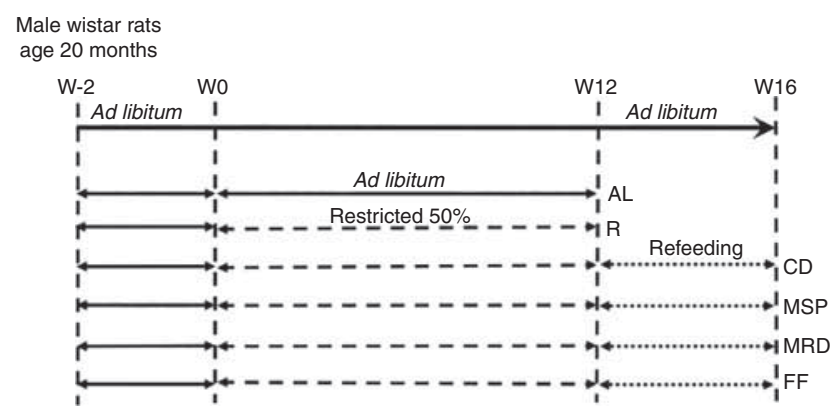

Figure 1

Food restriction and refeeding protocol for elderly Wistar rats. Elderly (20-month-old) Wistar rats were fed chow diet for 2 weeks and were then divided into six groups, as described in the 'Materials and methods' section. $A L$, ad libitum; R, restricted; CD, control diet; MSP, milk soluble protein; $M R D$, milk fat, rapeseed, and DHA; FF, full formula.

by the Local Ethics Committee for animal experimentation, Paris Center and South no. 59 (France), with authorization no. 91-519.

\section{Insulin responsiveness assay}

To evaluate insulin sensitivity following refeeding, each group was divided into two subgroups. Rats that were fasted overnight and then received either saline solution $(n=6)$ or insulin ( $1 \mathrm{U} / \mathrm{kg}$ of body weight, $n=6)$ bolus by i.p. injection $30 \mathrm{~min}$ before being killed.

\section{Metabolic and endocrine measures}

Body weight and food intake were measured once a week during the food restriction period and daily in the refed groups ( $n=18 /$ group).
Blood samples were collected from starved rats from all of the groups ( $n=6 /$ group) in heparinized tubes and centrifuged $(3500 \mathrm{t} / \mathrm{min}$ for $20 \mathrm{~min}$ ), and plasma was stored at $-80^{\circ} \mathrm{C}$ until analysis. Plasma glucose levels were measured using an Accu-Chek Performa kit (Roche). Plasma levels of insulin and leptin were measured using ELISA Kits (Millipore, Molsheim, France). Plasma Tnf $\alpha$ and Il6 levels were assayed by ELISA rat Tnf $\alpha$ and Il6 ELISA Kits (Invitrogen, Life Technologies), respectively, according to the manufacturer's instructions.

\section{Western blot analyses}

Following hormonal treatment, protein lysates from the hypothalamus, liver, and muscle were quickly removed, frozen in liquid nitrogen, and stored at $-80^{\circ} \mathrm{C}$. Samples were prepared for western blot analyses as previously described (Berthou et al. 2011). Briefly, samples were homogenized in $1 \mathrm{ml}$ lysis buffer $(10 \mathrm{mM}$ Tris- $\mathrm{HCl}(\mathrm{pH}$ 7.5), $150 \mathrm{mM} \mathrm{NaCl}, 1 \mathrm{mM}$ EGTA, $1 \mathrm{mM}$ EDTA, 0.5\% Nonidet-P40, and $1 \%$ Triton X-100), protease inhibitor cocktail $(0.35 \mathrm{mg} / \mathrm{ml}$ phenylmethylsulphonyl fluoride, $2 \mathrm{mg} / \mathrm{ml}$ leupeptin, and $2 \mathrm{mg} / \mathrm{ml}$ aprotinin), and phosphatase inhibitor cocktail (10 mM sodium fluoride, $1 \mathrm{mM}$ sodium orthovanadate, $20 \mathrm{mM}$ sodium b-glycerophosphate, and $10 \mathrm{mM}$ benzamidine) with Precellys 24/Cryolys (hypothalamus: $20 \mathrm{~s}$; liver and adipose tissue: $2 \times 20 \mathrm{~s}$ ). Homogenates were incubated for $2 \mathrm{~h}$ at $4{ }^{\circ} \mathrm{C}$ and then centrifuged (at $14000 \mathrm{~g}$ for $1 \mathrm{~h}$ at $4^{\circ} \mathrm{C}$ ), and the supernatants were stored at $-80^{\circ} \mathrm{C}$. Protein concentrations of the supernatants were determined using a protein assay kit (BCA Protein Assay Kit, Thermo

Table 2 Endocrine parameters and pro-inflammatory factors. Results are expressed as means \pm s.E.M.

Parameters
Endocrine parameters
$n$
Glycemia (mg/ml)
Insulinemia $(\mathrm{ng} / \mathrm{ml})$
Leptinemia $(\mathrm{ng} / \mathrm{ml})$
HOMA index
Pro-inflammatory factors
$n$
TNF $\alpha(\mathrm{pg} / \mathrm{ml})$
IL6 (ng/ml)

\begin{tabular}{c} 
\\
\\
Ad libitum (AL) \\
\hline 6 \\
$1.1 \pm 0.05^{\mathrm{a}}$ \\
$1.07 \pm 0.33^{\mathrm{a}}$ \\
$10.79 \pm 1.15^{\mathrm{b}}$ \\
$0.36 \pm 0.92^{\mathrm{a}, \mathrm{b}}$ \\
6 \\
$17.44 \pm 2.42$ \\
$145.87 \pm 8.24$ \\
\end{tabular}

Restricted
(12 weeks)

Different letters indicate significant differences with at least $P<0.05$. http://joe.endocrinology-journals.org DOI: 10.1530/JOE-15-0076
(C) 2015 Society for Endocrinology Printed in Great Britain
Published by Bioscientifica Ltd 
Scientific, Courtaboeuf, France). Protein extracts (70 $\mu \mathrm{g})$ were subjected to SDS-PAGE and transferred on to Immobilon-FL membranes (Millipore). Blots were blocked with 5\% BSA (Euromedex, Strasbourg, France) and then immunoblotted with primary antibodies raised against phospho (p)-AKT(Ser473), AKT, insulin receptor (IR), p38-MAPK, $\beta$ and tubulin (Cell Signaling Technology, Danvers, MA, USA) overnight at $4{ }^{\circ} \mathrm{C}$. For protein detection, we used HRP-conjugated secondary antibodies and chemiluminescence (Amersham Biosciences, Life Technologies). The blots were finally scanned and quantified using the Carestream Molecular Imaging System 4000MM PRO (Carestream Health, Inc., Bagnolet, France). Relative protein quantities were normalized using $\beta$-tubulin antibodies.

\section{RNA extraction and quantitative RT-PCR}

Hypothalamus, liver, and adipose tissue (visceral fat) of elderly rats from all of the groups ( $n=18 /$ group) were quickly removed under RNAse-free conditions, immediately frozen in liquid nitrogen, and stored at $-80^{\circ} \mathrm{C}$. Total RNA was prepared for quantitative RT-PCR (qRT-PCR) as previously described (Benoit et al. 2013). Briefly, frozen samples of hypothalamus, liver, and adipose tissue were homogenized using a tissue homogenizer (Precellys 24), and RNA was extracted with TRIzol LS reagent (Invitrogen) according to the manufacturer's instructions. One microgram of total RNA was reverse transcribed (F-572L M-MuLV, Finnzymes, Fontenay-sous-bois, France) and subjected to qRT-PCR (Step-One, Applied Biosystems) using adequate primers and Fast SyberGreen Master Mix (Applied Biosystems). Relative cDNA quantities were calculated from cycle thresholds $(\mathrm{Ct})$ and normalized with the housekeeping gene $S 18$ (Rps18). All of the qRTPCR primers were purchased from Sigma, including those for Ucp2 (forward: 5'-TGGCGGTGGTCGGAGATAC-3', reverse: 5'-GGCAAGGGAGGTCGTCTGTC-3'), Ucp3 (forward: 5'-CCCAAAGGAACGGACCAC-3, reverse: 5'-GGTTCTGTAGGCATCCATAGTC-3'), Adipor1 (forward: 5'-GCTGGCCTTTATGCTGCTCG-3', reverse: 5'-TCTAGGCCGTAACGGAATTC-3'), Adipor2 (forward: 5'-CCACAA CCTTGCTTCATCTA-3', reverse: 5'-GATACTGAGGG GTGGCAAAC-3'), ObRb (forward: 5'-ACCACATACCTCCTCACACTA-3', reverse: 5'-AGCAGTCCAGCCTACACTCTT-3'), IR (forward: 5'-TGCCACCAATCCTTCCGTTCC-3', reverse: $5^{\prime}$-TCCTCCGCCTGCCTCTCC-3'), Npy (forward: 5'-ATGCTAGGTAACAAACG-3', reverse: 5'-ATGTAGTGTCGCAGAG-3), Il6 (forward: $5^{\prime}$-GTTGCCTTCTTG GGACTGATGTT-3', reverse: 5-ACTGGTCTGTTGTGGGT GG
TATC-3'), Tnf $\alpha$ (forward: $5^{\prime}$-CTCATTCCTGCTCGT GGC GG-3', reverse: 5'-CCGCTTGGTGGTTTGCTACGA-3'), Ampk (forward: 5'-GAATGGAAGGTAGTGAATGC-3', reverse: $5^{\prime}$-TAAAGTCTAGAAGATAGCTCCG-3'), and $18 \mathrm{~s}$ (forward: 5'-TCCCCGAGAAGTTTCAGCACAT-3', reverse: 5'-CTTCCCATCCTTCACGTCCTTC-3').

\section{Statistical analysis}

Statistical analyses were performed using the MannWhitney $U$ test for the endocrine parameter, signaling, and gene expression experiments. Two-way repeatedmeasures ANOVA was used to test changes in body weight and energy intake over time followed by the Bonferroni's post hoc test. The results are expressed as means \pm s.E.M., and $P<0.05$ was considered statistically significant.

\section{Results}

\section{The effects of food restriction and diet composition during refeeding on body weight gain in elderly Wistar rats}

We investigated the effect of food restriction and refeeding using different diets $(\mathrm{AL}, \mathrm{R}, \mathrm{CD}, \mathrm{MSP}, \mathrm{MRD}$, and FF) on the body weight gain of elderly (20-monthold) Wistar rats. Thus, there were six groups of rats. Rats were killed 30 days after the commencement of the refeeding period, except for the AL group members, which were killed before the food restriction period began. Rats were feed-restricted $(\mathrm{R} ;-50 \%$ of their regular

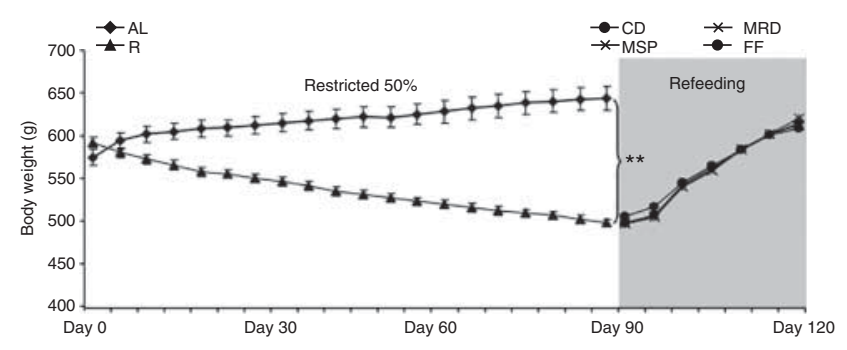

Figure 2

The effects of food restriction and refeeding in elderly Wistar rats. Elderly (20-month-old) Wistar rats were divided into two groups: ad libitum (AL) and restricted $(R,-50 \%$ of energy intake). These groups were maintained for 90 days under these regimens. The AL group members were killed at day 90, and the R group was then divided into five groups; one group was killed under the R state, and the other groups were refed with a control diet (CD), a milk soluble protein diet (MSP), a milk fat, rapeseed, and DHA (MRD) diet, or a full formula (FF) diet for an additional 30 days. Body weight was measured daily, and results are expressed as means \pm S.E.M., $n=18$. $* * P<0.001$.

Published by Bioscientifica Ltd 
A

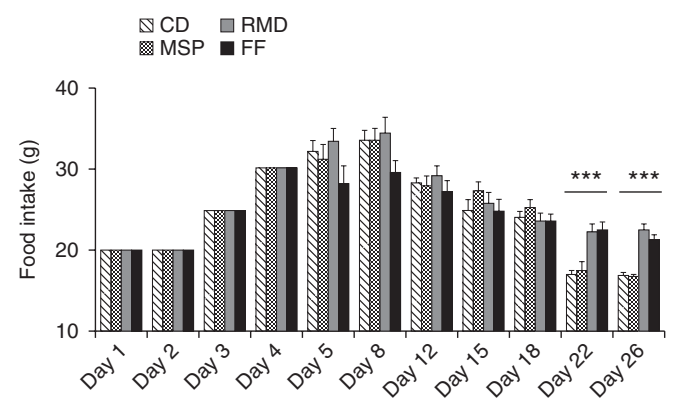

B
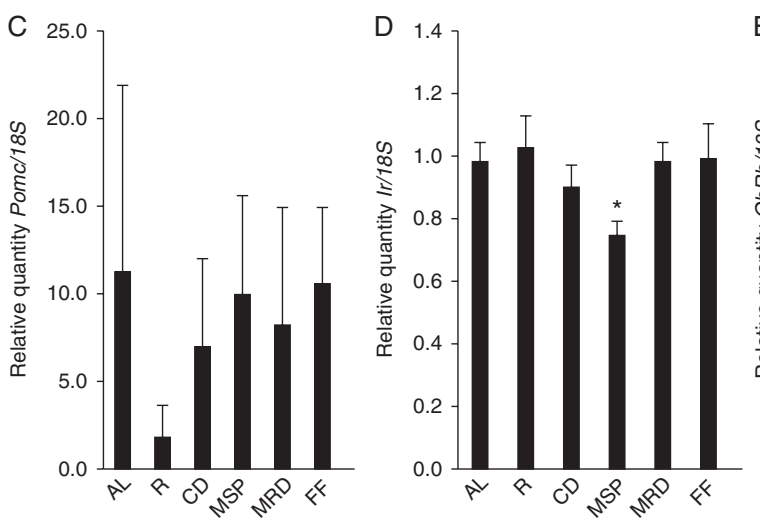
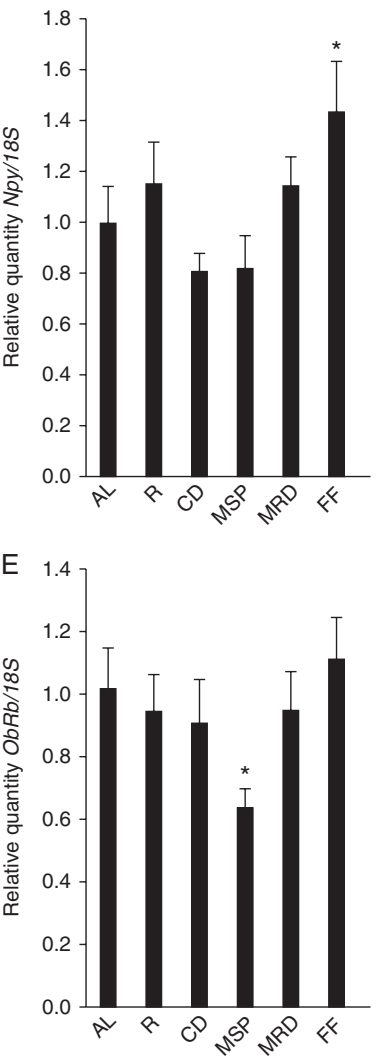

Figure 3

The effects of refeeding on food intake and the hypothalamic expression of Npy, Pomc, Ir, and leptin receptor. (A) Food intake (kcal/BW) was measured from days 4 to 26 of the refeeding period. Until day 8 , all of the refed groups received the same amount of food, and then all of the groups were allowed to refeed ad libitum with an adequate diet. Results are expressed as means \pm S.E.M., $n=18 . * * * P<0.001$. The hypothalamic expression of $N p y$
(B), Pomc (C), insulin receptor (Ir) (D), and leptin receptor (ObRb) (E) was measured by qRT-PCR analysis of total RNA extracted from all of the groups at the end of the experiment. Results were normalized to $18 \mathrm{~S}$ rRNA. Results are expressed as means \pm S.E.M., $n=18$. ${ }^{*} P<0.05$ when the FF group was compared with all of the other groups (B) and when the MSP group was compared with all of the other groups ( $D$ and $E$ ).
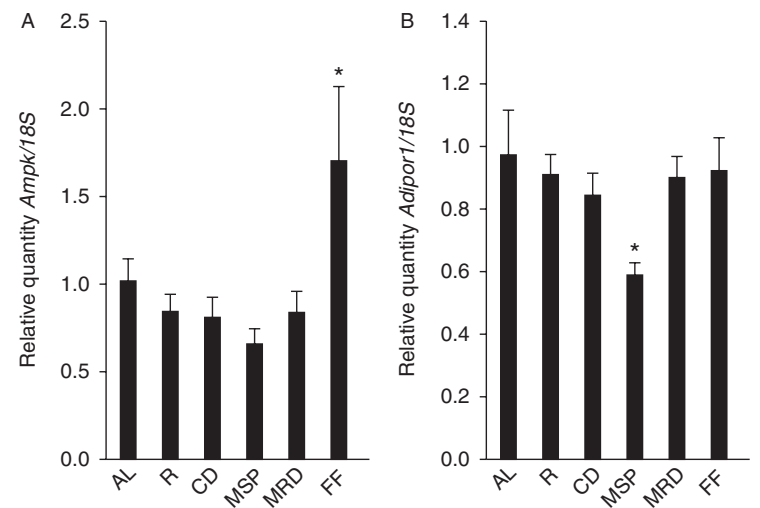
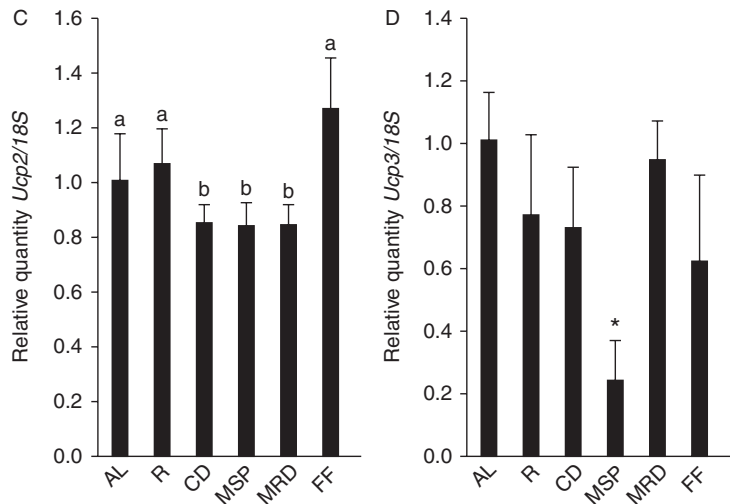

Figure 4

The effects of food restriction and refeeding on the hypothalamic expression of genes involved in energy homeostasis. After the rats were killed and the hypothalami were extracted, total RNA from each of the groups was subjected to qRT-PCR using adequate primers to quantify (A) Ampk, (B) Adipor1, (C) Ucp2, and (D) Ucp3 expression. Results were

\begin{tabular}{|lr} 
http://joe.endocrinology-journals.org & ( 2015 Society for Endocrinology \\
DOI: $10.1530 / J O E-15-0076$ & Printed in Great Britain
\end{tabular}

normalized to $18 \mathrm{~S}$ rRNA. Results are expressed as means \pm S.E.M., $n=18$. For Ampk expression, $* P<0.05$ when the FF group was compared with all of the other groups. For Adipor1 and Adipor2, ${ }^{*} P<0.05$ when the MSP group was compared with all of the other groups. For Ucp2, different superscript letters denote significant differences at $P<0.05$.

Published by Bioscientifica Ltd 


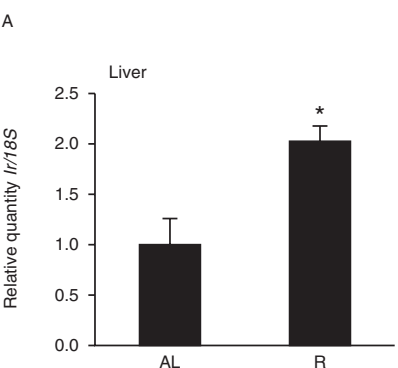

B
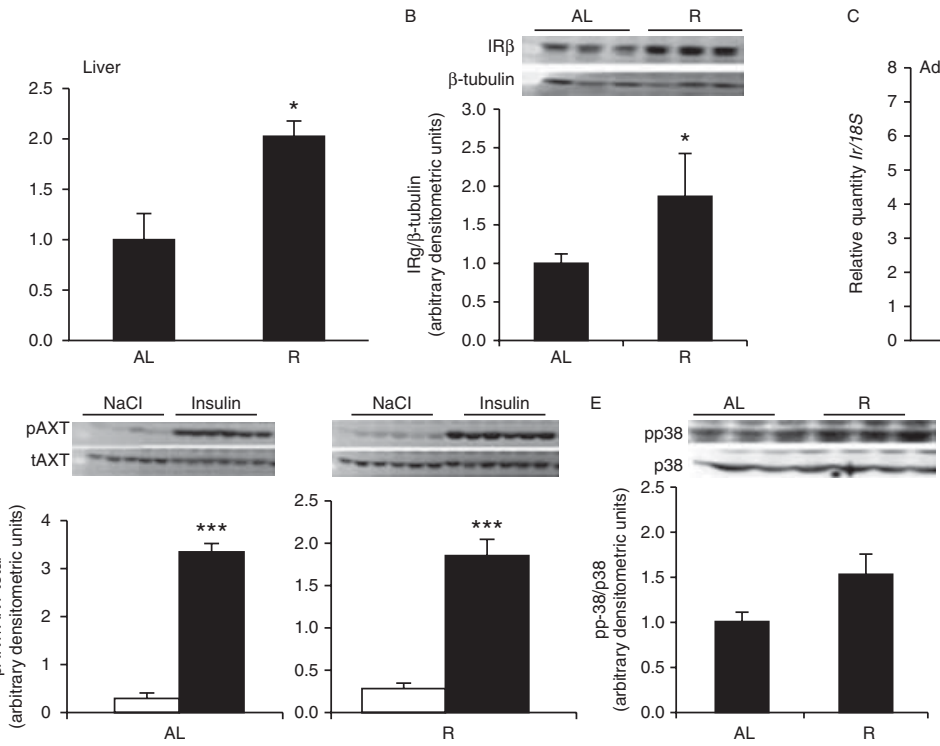

C
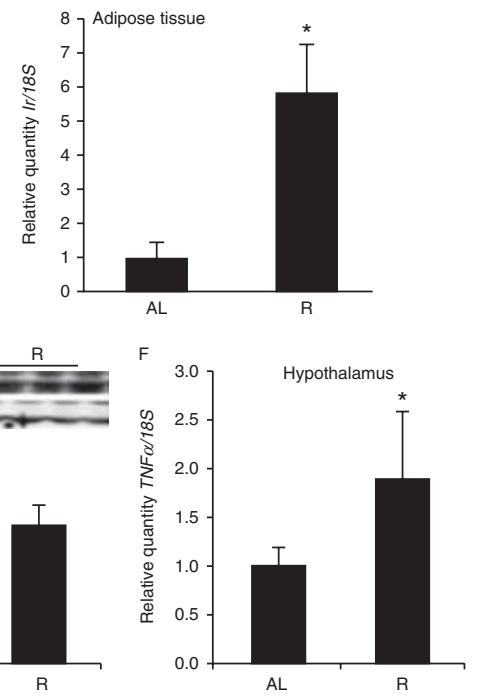

\section{Figure 5}

The effects of food restriction on insulin signaling in the liver and on hypothalamic inflammation in elderly Wistar rats. (A) Liver mRNA samples from the $A L$ and $R$ groups were subjected to $q R T-P C R$ using primers to amplify IR, and results were normalized using $18 \mathrm{~S}$ rRNA. Results are expressed as means \pm S.E.M., $n=18$. ${ }^{\star} P<0.05$ when comparing the AL group with the R group. (B) Proteins were prepared from the livers of the $A L$ and $R$ groups and were subjected to western blot analysis using antibodies directed toward $I R$, and results were normalized to $\beta$-tubulin. Results are expressed as means \pm S.E.M., $n=18$. ${ }^{*} P<0.05$ when comparing the AL group with the $R$ group. (C) Adipose tissue samples from the $A L$ and $R$ groups were subjected to qRT-PCR using primers to amplify IR, and results were normalized using $18 \mathrm{~S}$ rRNA. Results are expressed as means \pm s.E.M., $n=18$. ${ }^{*} P<0.05$ when comparing the AL group with the R group. (D) To evaluate insulin responsiveness, the $\mathrm{Al}$ and $\mathrm{R}$ groups received a bolus insulin or placebo treatment, and then liver proteins were solubilized and subjected to western blot analysis using antibodies directed toward phosphorylated AKT ( $p A K T)$. Results were normalized using antibodies directed toward total AKT (tAKT). Results are expressed as means \pm s. E.M., $n=6 . * * * P<0.001$ when comparing insulin-treated animals with animals treated with saline. (E) To determine the effects of restriction on the phosphorylation of p38-MAPK, solubilized proteins from the livers of AL and R groups were subjected to western blot analysis using antibodies directed toward phosphorylated p38 (pp38), and results were normalized to total p38 (p38). Results are expressed as means \pm S.E.M., $n=6$. ${ }^{*} P<0.05$. (F) Hypothalamic RNA samples from the AL and R groups were subjected to qRT-PCR using primers to amplify TNF $\alpha$, and results were normalized using 185 rRNA. Results are expressed as means \pm S.E.M., $n=18 .{ }^{*} P<0.05$ when comparing the $A L$ group with the $R$ group. intake) for 90 days and were then allowed to refeed AL for 30 days with a CD, MSP, MRD, or FF diet, except for the R group, which was killed at the end of the food restriction period (Fig. 1). Before the food restriction, rats exhibited a body weight of $581.8 \pm 12.9 \mathrm{~g}$, and following restriction, they had lost $104.63 \pm 4.3 \mathrm{~g}$. All of the refed groups gained a similar amount of weight despite their different diets (Fig. 2), with a mean body weight of $623.6 \mathrm{~g}$.

\section{The effects of diet composition during refeeding on food intake and the hypothalamic expression of $\mathrm{Npy}$, Pomc, IR, and leptin receptor}

During the early stage of refeeding (until day 18) all of the groups ingested similar amounts of food, but at days 22 and 26, the MRD and FF groups exhibited a higher food intake as compared with the CD and MSP groups (Fig. 3A). To investigate whether these changes were due to changes in the expression levels of hypothalamic neuropeptides and receptors that are involved in the control of food intake, we measured the expression levels of Npy, Pomc, IR, and $O b R b$. Npy expression was significantly increased in the FF group as compared with the other groups (Fig. 3B), whereas Pomc expression was not modified (Fig. 3C). In addition, we observed downregulation of both $I R$ and $O b R b$ in the MSP group as compared with all of the other groups (Fig. 3D and E). No changes were observed between the $\mathrm{CD}$ and $\mathrm{R}$ groups.

\section{The effects of diet composition during refeeding on the hypothalamic expression of genes involved in cellular energy sensing}

To analyze the effects of diet composition during refeeding on hypothalamic markers of energy sensing, the expression levels of Ampk, Adipor1, Ucp2, and Ucp3 were

Published by Bioscientifica Ltd. 
A
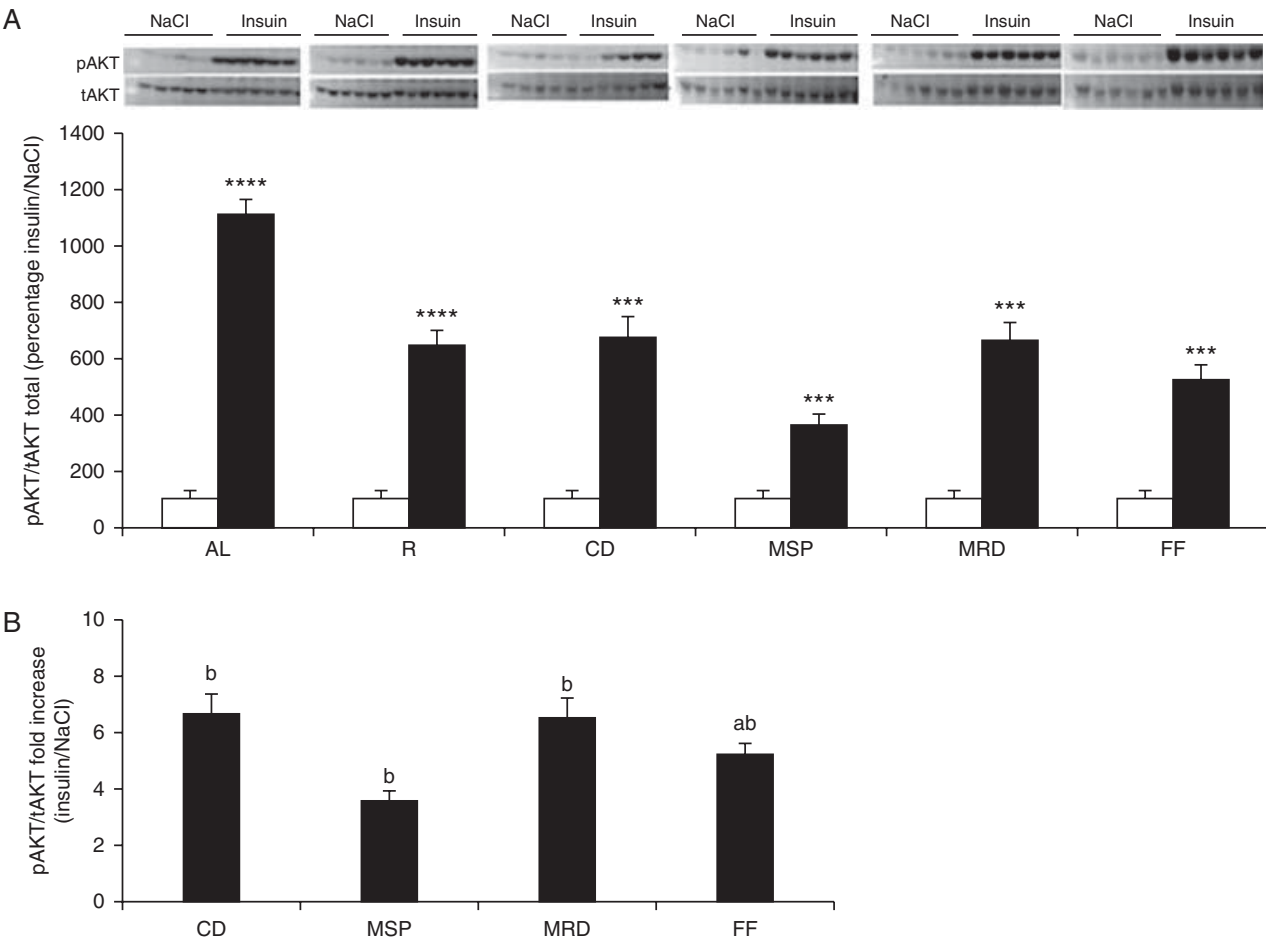

\section{Figure 6}

The effects of refeeding on insulin responsiveness in the livers of elderly Wistar rats. (A) Liver protein from the AL, R, CD, MSP, MRD, and FF groups was solubilized and subjected to western blot analysis using antibodies directed toward phosphorylated AKT (pAKT). Results were normalized to total AKT (tAKT) using specific antibodies. Bands were quantified using a Carestream apparatus and quantified using Carestream Software

determined. We observed that Ampk expression was significantly increased in the FF group as compared with the other refed groups (Fig. 4A). However, we showed that the mRNA levels of Adipor1 (Fig. 4B) and Ucp3 (Fig. 4D) were significantly reduced in the MSP group as compared with the other groups. Figure $4 \mathrm{C}$ shows that $U c p 2$ expression was downregulated in the CD, MSP, and MRD groups as compared with the $\mathrm{FF}, \mathrm{AL}$, and $\mathrm{R}$ groups.

\section{The effects of food restriction and refeeding on endocrine parameters and insulin responsiveness in elderly rats}

We showed that food restriction was associated with a significant decrease in the plasma levels of glucose and insulin and a reduced HOMA index as compared with the AL group (Table 2). Refeeding for 30 days increased the plasma levels of insulin and leptin in all of the refed groups so that they reached the levels of the AL group (Table 2). In addition, the HOMA index was also restored. It is noteworthy that plasma insulin levels were lower in the FF group as compared with the other refed groups.
(Carestream, Bagnolet, France). Results are expressed as means \pm s.E.M. of pAkt/tAkt (\%insulin/ $/ \mathrm{NaCl}), n=6 . * * * P<0.0005$ and $* * * * P<0.0001$.

(B) Comparison between the refed groups regarding the insulin-dependent AKT phosphorylation response amplitude (insulin/saline). Results are expressed as means \pm s.E.M., $n=6$ and different superscript letters denote significant differences at $P<0.05$.

However, pro-inflammatory factors (Il6 and Tnfo) were not affected by restriction or by the quality of diet during the refeeding (Table 2).

\section{The effects of food restriction and refeeding on liver insulin sensitivity}

We investigated the effects of food restriction on insulin sensitivity in elderly rats by measuring IR expression in liver and adipose tissue. We showed that restriction induced the upregulation of IR in both liver and adipose tissue (Fig. 5A, B and C). However, insulin-dependent Akt phosphorylation in the liver was not significantly modified by food restriction, and insulin was able to phosphorylate AKT in both the AL and R groups (Fig. 5D). However, the amplitude of response in the $\mathrm{R}$ group was less pronounced than that in the AL group. In addition, food restriction led to an augmentation of inflammation markers in the liver and the hypothalamus. Indeed, food restriction increased p38MAPK phosphorylation in the liver and Tnf $\alpha$ expression in the hypothalamus (Fig. 5E and $\mathrm{F}$ respectively).

Published by Bioscientifica Ltd. 

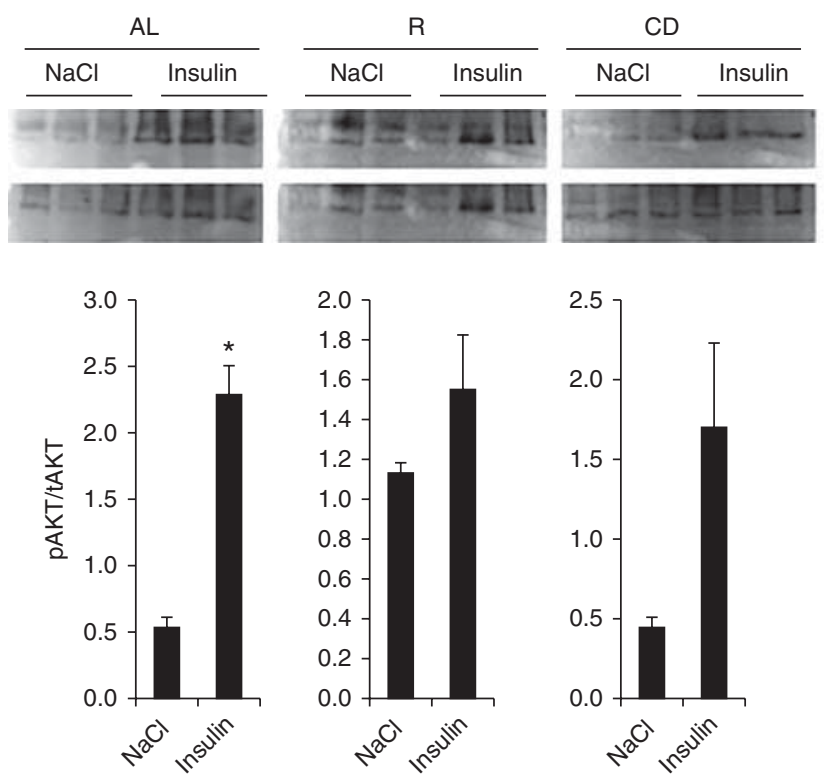

Figure 7

The effects of refeeding on insulin responsiveness in the muscle of elderly Wistar rats. Muscle protein from the AL, R, CD, MSP, MRD, and FF groups was solubilized and subjected to western blot analysis using antibodies directed toward phosphorylated AKT. Results were normalized to total AKT

To investigate the effects of diet composition during refeeding on insulin-responsiveness, AKT phosphorylation was measured in response to insulin challenge. We showed that insulin significantly increased AKT phosphorylation in the liver in all of the groups (Fig. 6A). However, the amplitude of response was significantly lower in the MSP group as compared with the other refed groups (Fig. 6B).

\section{The effects of food restriction and refeeding on muscle insulin-dependent AKT phosphorylation}

To investigate the effects of food restriction and diet composition during refeeding on insulin-responsiveness, muscle AKT phosphorylation was measured in response to insulin challenge. We showed that insulin significantly increased muscle AKT phosphorylation in the AL group and that this augmentation was abolished in the $\mathrm{R}$ group. Concerning the refed groups, insulin responsiveness was restored in the MRD group, which exhibited a significant increase in insulin-dependent AKT phosphorylation. The FF group exhibited a slight increase in insulin-dependent AKT phosphorylation $(P=0.06)$, whereas the CD and MSP groups showed lower insulin responsiveness (Fig. 7).
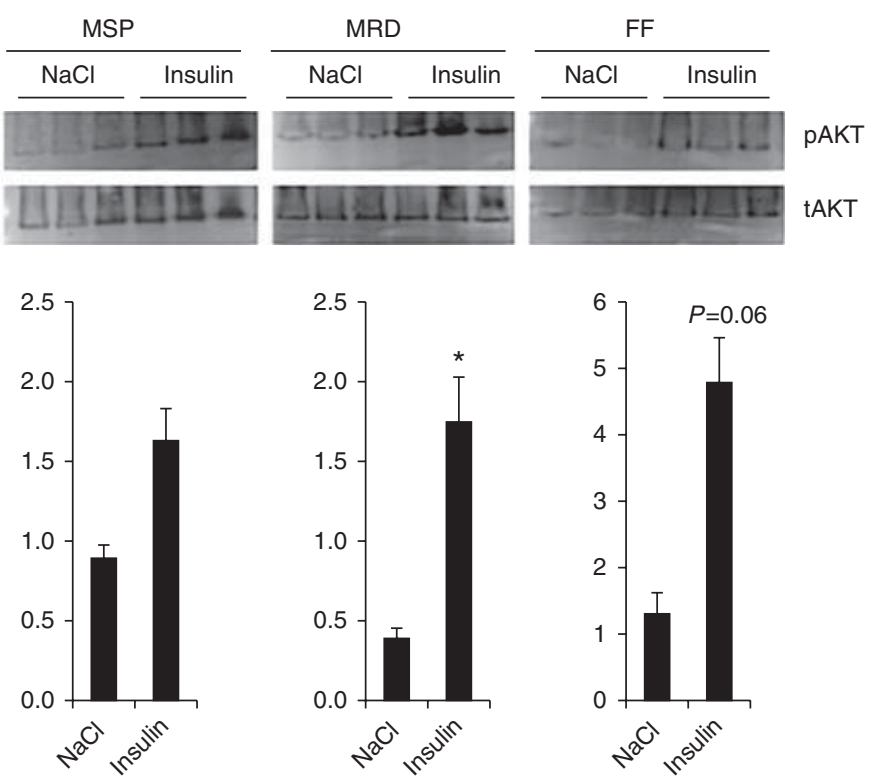

using specific antibodies. Bands were quantified using a Carestream apparatus and quantified using Carestream Software. Results are expressed as means \pm s. E.M., $n=6$. ${ }^{*} P<0.05$.

\section{The effects of food restriction and refeeding on the expression of adiponectin receptor, IR, and AMPK in the liver}

To investigate the effects of diet composition on cellular energy sensing in liver, we studied the changes in adiponectin receptor and AMPK expression. Following food restriction and refeeding with different diets, the expression levels of ADIPOR1, ADIPOR2, and AMPK in the liver were assessed by qRT-PCR. No differences were observed between the different groups before or during food restriction nor during refeeding, except that the expression of ADIPOR1, ADIPOR2, and AMPK was significantly increased in the $\mathrm{CD}$ group as compared with the AL, R, MSP, MRD, and FF groups (Fig. 8A, B and $\mathrm{C}$ ). We also showed that IR was upregulated in the $\mathrm{R}$ group as compared with the AL and FF groups, whereas IR in the CD, MSP, and MRD groups was significantly increased as compared with the $\mathrm{AL}$ group but not as compared with the FF and R groups (Fig. 8D).

\section{The effects of refeeding on liver pro-inflammatory factors}

To determine the effect of refeeding on liver inflammation, we compared the expression levels of TNF $\alpha$ and IL6 in the livers of refed groups with the AL and R groups. The expression of TNF $\alpha$ was significantly higher in the $\mathrm{AL}$

Published by Bioscientifica Ltd 

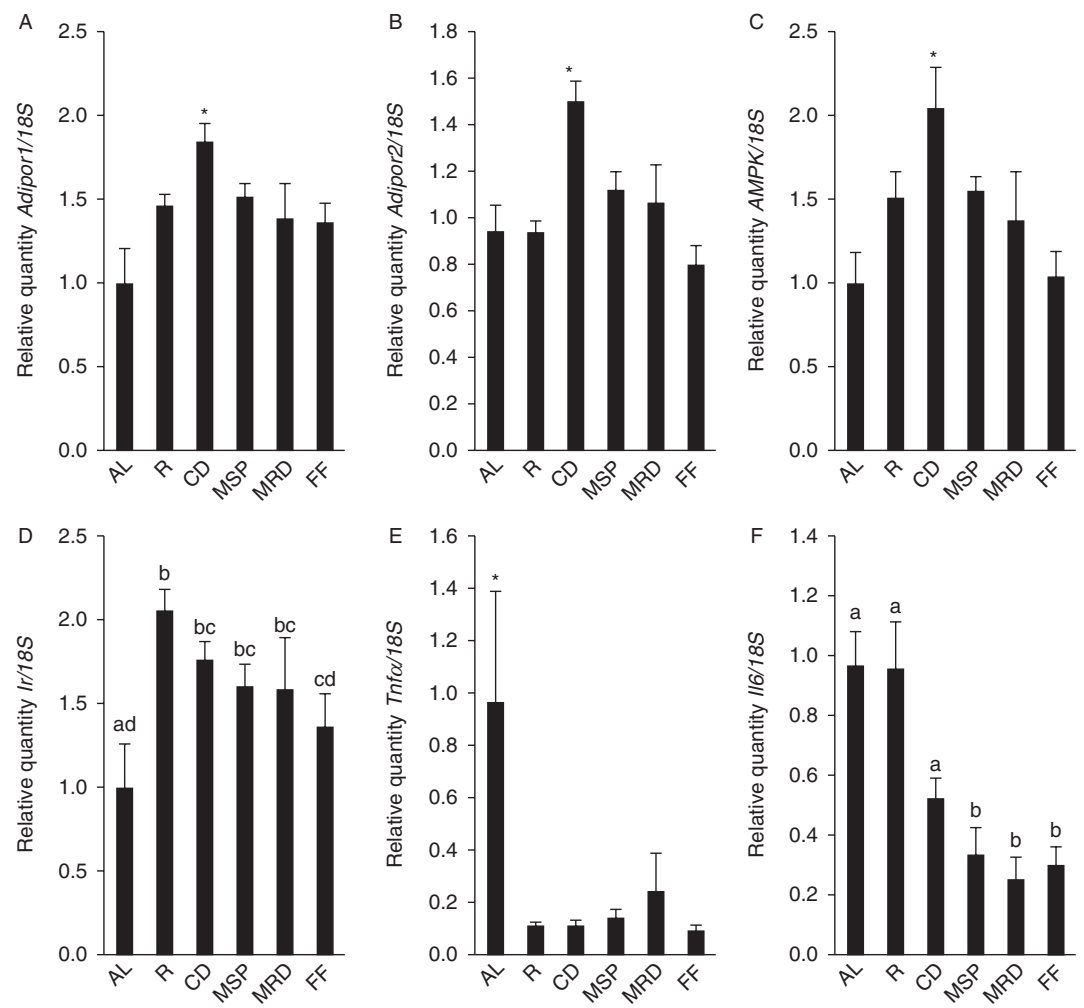

\section{Figure 8}

The effects of refeeding on liver genes that are involved in energy homeostasis and inflammation. After the rats were killed and the livers were extracted, total RNA from all of the groups was subjected to qRT-PCR using appropriate primers for Adipor1 (A), Adipor2 (B), Ampk (C), Tnf $\alpha$ (D),

group as compared to the $\mathrm{R}$ group, and this diminution was maintained independently of the composition of the refeeding diet (Fig. 8E). IL6 expression was significantly higher in the AL and R groups as compared with all of the refed groups, and this increase was maintained independently of diet composition (Fig. 8F).

\section{The effects of food restriction and refeeding on the hypothalamic expression of TNF $\alpha$ and IL6}

To determine the potential effects of the different diets that were used during the refeeding period on hypothalamic inflammation, we measured the expression of two markers: TNF $\alpha$ and IL6. We showed that food restriction significantly increased the expression of TNF $\alpha$, and refeeding, independently of diet composition, reduced the expression of TNF $\alpha$ so that it reached the same level as that for the AL group (Fig. 9A). We also showed that IL6 expression was significantly reduced in the FF group as compared with all of the other groups, including the $\mathrm{R}$ and AL groups (Fig. 9B). and $/ 16$ (E). Results were normalized to 185 rRNA and are expressed as means \pm s.E.M., $n=18$. $* P<0.05$ when samples were compared with all of the groups (A, B, C and $E$ ), and different superscript letters denote significant differences at $P<0.05$ ( $D$ and $F$ ).

\section{Discussion}

Nutritional manipulation is now considered one of the most promising solutions for overcoming, or at least attenuating, many age-related disorders and diseases, such as atherosclerosis, cancer, diabetes, sarcopenia, metabolic syndrome, inflammation, and obesity. Indeed, many reports have revealed increased malnutrition in the elderly that is associated with frailty, a decline in muscle mass, and an impairment of energy homeostasis control. Among the nutrients that have been extensively studied as potential candidates for nutritional manipulation during aging, protein takes an important place. Indeed, the focus on protein has been driven by the important loss of skeletal muscle that could be, at least partially, attributed to amino acid availability (Fukagawa 2013). Besides protein, carbohydrates, and fat have been also given much attention because of the metabolic disorders that are associated with these macronutrients in the elderly (such as insulin resistance, type 2 diabetes, and obesity). However, nutritional manipulations are complex because

Published by Bioscientifica Ltd. 

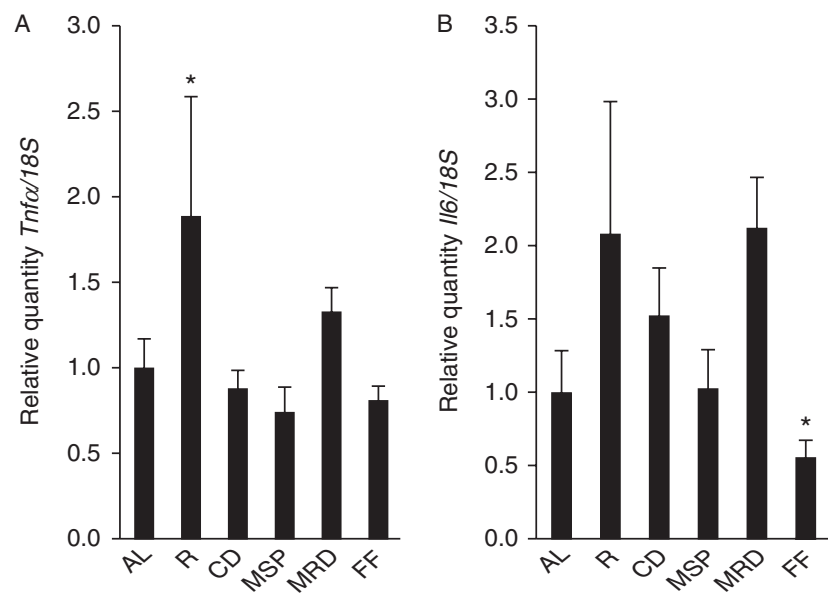

Figure 9

The effects of food restriction and refeeding on hypothalamic genes that are involved in inflammation. After the rats were killed and the hypothalami were extracted, total RNA from all of the groups was subjected to qRT-PCR using appropriate primers for $\operatorname{Tnf} \alpha$ (A) and $/ / 6$ (B) expression. Results were normalized to 185 rRNA and are expressed as means \pm s. E.M., $n=18$. ${ }^{*}<<0.05$ when samples were compared with the AL group.

macronutrients such as protein, fat, and carbohydrates are involved in the regulation of food intake through amino acids, fatty acids, and glucose respectively, and this could interfere with the theoretical efficacy of each nutrient. To add to this complexity, the combination of nutrients with different qualities, compositions, and energy values could also play a role in the diet of the elderly and its efficiency and availability.

In the present study, we aimed to analyze the effects of diets that differed in terms of their protein and fat quality on insulin responsiveness, inflammation, and the expression of genes that are involved in the control of energy homeostasis in elderly undernourished Wistar rats. Special attention was paid to the combination of MSP and milk lipids.

To mimic malnutrition in elderly humans, we subjected elderly (20-month-old) rats to food restriction $(-50 \%)$ for 12 weeks, and this led, as expected, to a significant reduction in body weight accompanied by diminished glucose, insulin, and leptin plasma levels. Food restriction induced the upregulation of IR in liver and adipose tissue, and it maintained liver insulindependent AKT phosphorylation as compared with the $\mathrm{AL}$ group. However, it is noteworthy that the insulin responsiveness of the $\mathrm{R}$ group was weaker as compared with the AL group. This was mostly a result of the striking reduction in plasma insulin levels. Food restriction in elderly rats induced the augmentation of p38-MAPK phosphorylation in the liver, which is generally considered to be a marker of cellular inflammation and is believed to promote insulin sensitivity (Qi et al. 2013). Food restriction also increased pro-inflammatory factor TNF $\alpha$ in the hypothalamus. This impairment is in accordance with the alteration in insulin signaling that we observed, but it contradicts our hypothesis that food restriction would not alter insulin-dependent AKT phosphorylation in the liver; it may be explained by a degree of insulin alteration. Indeed, food restriction reduced insulin plasma levels but most probably increased animal stress, which may have contributed to the onset of hypothalamic inflammation and the activation of liver p38-MAPK (García-San Frutos et al. 2012). It is noteworthy that food restriction has the opposite effect on liver TNF $\alpha$ to that which it has on the hypothalamus. Indeed, food restriction downregulated liver TNF $\alpha$ as compared with the AL group. It has been suggested that aging increases liver $\mathrm{TNF} \alpha$ and apoptosis and that food restriction reduces hepatic apoptosis, and this may explain the hepatic downregulation of TNF $\alpha$ (Ando et al. 2002). Importantly, we also showed that muscle insulin responsiveness exhibited different features from that of the liver. Indeed, food restriction abolished muscle insulin-dependent AKT phosphorylation as compared with the AL group. Interestingly both the MRD and FF groups exhibited total or partial restoration of muscle insulin responsiveness respectively. This effect could contribute to better protein deposition in these two groups, which indicates a beneficial effect of milk fat combined with DHA and MSP. Further experiments are needed to directly measure muscle protein synthesis.

Following food restriction, we refed four groups with diets that differed in terms of their protein content, fat quality, and VitD. Independently of diet quality, we showed that all of the refed groups displayed similar gains in body weight and almost reached the body weight of the AL group. This body weight catch-up reached almost $80 \%$ within 4 weeks of refeeding and was associated with a significant increase in plasma leptin levels in all of the groups. However, plasma insulin levels were significantly increased in all of the refed groups as compared with the R groups, but the FF group exhibited significantly lower plasma insulin levels as compared with the CD, MSP, and MRD groups. Thus, in the FF group, the plasma glucose level was similar to that of all of the other refed groups, and this could be attributed to better insulin responsiveness. Indeed, the FF contained both milk fat and MSP with high concentrations of VitD. Furthermore, the FF group exhibited a higher food intake, which was

Published by Bioscientifica Ltd 
correlated with the upregulation of orexigenic neuropeptide Npy in the hypothalamus. Similar results concerning food intake were obtained in the MRD group but this group did not exhibit significant changes in Npy and Pomc expression. The MRD group's increased food intake could probably by attributed to other mechanisms that have not yet been elucidated. The FF and MRD diets share in common a similar content of MRD. Thus, we suggest that fat quality increased the appetence for these two diet combinations. However, the combination of milk fat with MSP and high VitD concentrations seems to have had a beneficial effect as compared with the MRD group, as was evidenced by the reduced expression of pro-inflammatory cytokine Il6 in the hypothalamus of the FF group. Indeed, it has been reported that hypothalamic inflammation is implicated in the alteration of neural circuitry and in the subsequent impairment of energy homeostasis regulation (Meng \& Cai 2011). Thus, these beneficial effects of FF formulation are probably a result of the combination of MSP, milk fat-associated LC-omega-3 fatty acids, and high doses of VitD. Indeed, whey protein has been shown to improve insulin responsiveness (Arciero et al. 2014), and VitD supplementation has been shown to reduce neuroinflammation (Adzemovic et al. 2013). Furthermore, VitD deficiency promotes cognitive decline (Keeney et al. 2013). In addition, the protective effects of omega- 3 fatty acids have been previously described in terms of their ability to prevent insulin resistance, inflammation, and neuroinflammation (Figueras et al. 2011, Kalupahana et al. 2011, Oliver et al. 2012). The FF group also exhibited the upregulation of hypothalamic Ampk as compared with all of the other groups, and this finding provides evidence supporting the beneficial effect of this formula. Indeed, hypothalamic Ampk has been described as a crucial energy sensor that is essential in the hypothalamic integration of hormonal and nutritional signals (Schneeberger \& Claret 2012). It is noteworthy that $U c p 2, U c p 3$, and Adipor 1 were downregulated in the MSP group, which indicates a potential defect in glucose sensing at the hypothalamic level. Indeed, Ucp2 and Adipor1 (the receptor that activates the Ampk cascade) are important regulators of neuronal glucose and energy sensing (Guillod-Maximin et al. 2009, Toda \& Diano 2014). This accords with the reduced expression levels of hypothalamic leptin and IRs.

At the hepatic level, we showed that in all of the groups Adipor1, Adipor2, and Ampk were not significantly modified, except in the CD group, where these cellular energy sensors were upregulated. This was most probably caused by the higher sensitivity of the $\mathrm{CD}$ group to the fasted state, seeing as the entire experiment was performed in a fasted state. It has been previously shown that the expression of Adipor 1 is increased under fasting conditions and is decreased after refeeding (Dridi \& Taouis 2009).

Taken together, the present results indicated that: i) food restriction led to the upregulation of IR in the liver, hypothalamus, and adipose tissue and was accompanied by increased pro-inflammatory TNF $\alpha$ in the hypothalamus of elderly Wistar rats; ii) in all of the refed groups, refeeding led to similar body weight gain by the end of a 4-week refeeding period; iii) refeeding with a blend of MRD (or FF) induced higher food intake; and iv) the combination of MSP and milk fat in the presence of VitD and omega-3 PUFA (the FF group) reduced hypothalamic Il6 expression.

\section{Declaration of interest}

The authors declare that there is no conflict of interest that could be perceived as prejudicing the impartiality of the research reported.

\section{Funding}

This study was supported by the Agence Nationale de la Recherche (ANR, French Agency for Research; grant number ANR-2010-ALLIA-013-05 PRESAGE).

\section{Author contribution statement}

$\mathrm{HO} \mathrm{H}$ performed most of the experiments and participated in writing the manuscript; $B$ D participated in designing the experiment, interpreting the nutritional data, and revising the manuscript; $Y B$ performed some of the experiments; $D C$ performed most of the qRT-PCR experiments; $L R$ performed most of the ELISA analyses; $P$ L and C B provided the specific diets and contributed to the experimental design and to the manuscript revision; M T designed and supervised the study and wrote the paper. All of the authors read and approved the final manuscript.

\section{Acknowledgements}

We thank all of our colleagues who were involved in PRESAGE for their fruitful discussions and comments, including S Walrand, J C Martin, Y Rolland, and D Séguy. We are also thankful to J Lefebvre for the animal care.

\section{References}

Adzemovic MZ, Zeitelhofer M, Hochmeister S, Gustafsson SA \& Jagodic M 2013 Efficacy of vitamin D in treating multiple sclerosis-like neuroinflammation depends on developmental stage. Experimental Neurology 249 39-48. (doi:10.1016/j.expneurol.2013.08.002)

Akinkuoliea AO, Ngwaa JS, Meigsb JB \& Djousséc L 2011 Omega-3 polyunsaturated fatty acid and insulin sensitivity: a meta-analysis of randomized controlled trials. Clinical Nutrition 30 702-770. (doi:10.1016/j.clnu.2011.08.013)

Ando K, Higami Y, Tsuchiya T, Kanematsu T \& Shimokawa I 2002 Impact of aging and life-long calorie restriction on expression of apoptosis- 
related genes in male F344 rat liver. Microscopy Research and Technique 59 293-300. (doi:10.1002/jemt.10207)

Arciero PJ, Baur D, Connelly S \& Ormsbee MJ 2014 Timed-daily ingestion of whey protein and exercise training reduces visceral adipose tissue mass and improves insulin resistance: the PRISE study. Journal of Applied Physiology 117 1-10. (doi:10.1152/japplphysiol.00152.2014)

Benoit C, Ould-Hamouda H, Crepin D, Gertler A, Amar L \& Taouis M 2013 Early leptin blockade predisposes fat-fed rats to overweight and modifies hypothalamic microRNAs. Journal of Endocrinology 218 35-47. (doi:10.1530/JOE-12-0561)

Berthou F, Rouch C, Gertler A, Gerozissis K \& Taouis M 2011 Chronic central leptin infusion differently modulates brain and liver insulin signaling. Molecular and Cellular Endocrinology 337 89-95. (doi:10.1016/ j.mce.2011.02.005)

Biolo G, Cederholm T \& Muscaritoli M 2014 Muscle contractile and metabolic dysfunction is a common feature of sarcopenia of aging and chronic diseases: from sarcopenic obesity to cachexia. Clinical Nutrition 33 737-748. (doi:10.1016/j.clnu.2014.03.007)

Cancelas J, Prieto PG, Villanueva-Penacarrillo ML, Zhang Y, Portois L, Sener A, Carpentier YA, Valverde I \& Malaisse WJ 2007 Glucose intolerance associated to insulin resistance and increased insulin secretion in rats depleted in long-chain $\omega 3$ fatty acids. Hormone and Metabolic Research 39 823-825. (doi:10.1055/s-2007-991171)

Cardoso S, Correia S, Santos RX, Carvalho C, Santos MS, Oliveira CR, Perry G, Smith MA, Zhu X \& Moreira P 2009 Insulin is a two-edged knife on the brain. Journal of Alzheimer's Disease 18 483-507. (doi:10.3233/ JAD-2009-1155)

Chernoff R 2005 Micronutrient requirements in older women. American Journal of Clinical Nutrition 81 1240-1245.

Chung HY, Cesari M, Anton S, Marzetti E, Giovannini S, Seo AY, Carter C, Yu BP \& Leewenburgh C 2009 Molecular inflammation: underpinnings of aging and age-related diseases. Ageing Research Reviews 8 19-30. (doi:10.1016/j.arr.2008.07.002)

Dangin M, Guillet C, Garcia-Rodenas C, Gachon P, Bouteloup-Demange C, Reiffers-Magnani K, Fauquant J, Ballèvre O \& Beaufrère B 2003 The rate of protein digestion affects protein gain differently during aging in humans. Journal of Physiology 549 635-644. (doi:10.1113/jphysiol. 2002.036897)

Dridi S \& Taouis M 2009 Adiponectin and energy homeostasis: consensus and controversy. Journal of Nutritional Biochemistry 20 831-839. (doi:10.1016/j.jnutbio.2009.06.003)

Escrivá F, Gavete ML, Fermín Y, Pérez C, Gallardo N, Alvarez C, Andrés A, Ros M \& Carrascosa JM 2007 Effect of age and moderate food restriction on insulin sensitivity in Wistar rats: role of adiposity. Journal of Endocrinology 194 131-141. (doi:10.1677/joe.1.07043)

Figueras M, Olivan M, Busquets S, López-Soriano FJ \& Argilés JM 2011 Effects of eicosapentaenoic acid (EPA) treatment on insulin sensitivity in an animal model of diabetes: improvement of the inflammatory status. Obesity 19 362-369. (doi:10.1038/oby.2010.194)

Foster MT, Shi H, Seeley RJ \& Woods SC 2010 Transplantation or removal of intra-abdominal adipose tissue prevents age-induced glucose insensitivity. Physiology \& Behavior 101 282-288. (doi:10.1016/j. physbeh.2010.05.014)

Fukagawa NK 2013 Protein and amino acid supplementation in older humans. Amino Acids 44 1493-1509. (doi:10.1007/s00726-013-1480-6)

Fulop T, Larbi A, Witkowski JM, McElhaney J, Loeb M, Mitnitski A \& Pawelec G 2010 Aging, frailty and age-related diseases. Biogerontology 11 547-563. (doi:10.1007/s10522-010-9287-2)

García-San Frutos M, Fernández-Agulló T, Carrascosa JM, Horrillo D, Barrús MT, Oliveros E, Sierra J \& Ros M 2012 Involvement of protein tyrosine phosphatases and inflammation in hypothalamic insulin resistance associated with ageing: effect of caloric restriction. Mechanisms of Ageing and Development 133 489-497. (doi:10.1016/j. mad.2012.06.001)

German JB, Gibson RA, Krauss RM, Nestel P, Lamarche B, Van Staveren WA, Steinjns JM, De Groot LC, Lock AL \& Destaillats F 2009 A reappraisal of the impact of dairy foods and milk fat on cardiovascular disease risk. European Journal of Nutrition 48 191-203. (doi:10.1007/s00394-0090002-5)

Guillet C, Prod'homme M, Balage M, Gachon P, Giraudet C, Morin L, Grizard J \& Boirie Y 2004 Impaired anabolic response of muscle protein synthesis is associated with S6K1 dysregulation in elderly humans. FASEB Journal 18 1586-1587. (doi:10.1096/fj.03-1341fje)

Guillod-Maximin E, Roy AF, Vacher CM, Aubourg A, Bailleux V, Lorsignol A, Pénicaud L, Parquet M \& Taouis M 2009 Adiponectin receptors are expressed in hypothalamus and colocalized with proopiomelanocortin and neuropeptide $\mathrm{Y}$ in rodent arcuate neurons. Journal of Endocrinology 200 93-105. (doi:10.1677/JOE-08-0348)

Hirabara SM, Folador A, Fiamoncini J, Lambertucci RH, Rodrigues CF Jr, Rocha MS, Aikawa J, Yamazaki RK, Martins AR, Rodrigues AC et al. 2013 Fish oil supplementation for two generations increases insulin sensitivity in rats. Journal of Nutritional Biochemistry 24 1136-1145. (doi:10.1016/j.jnutbio.2012.08.014)

Holmberg S \& Thelin A 2013 High dairy fat intake related to less central obesity: a male cohort study with 12 years' follow-up. Scandinavian Journal of Primary Health Care 31 89-94. (doi:10.3109/02813432.2012. 757070)

Kalupahana NS, Claycombe KJ \& Moustaid-Moussa N 2011 (n-3) Fatty acids alleviate adipose tissue inflammation and insulin resistance: mechanistic insights. Advances in Nutrition 2 304-316. (doi:10.3945/an.111. 000505)

Katsanos CS, Kobayashi H, Sheffield-Moore M, Aarsland A \& Wolfe RR 2005 Aging is associated with diminished accretion of muscle proteins after the ingestion of a small bolus of essential amino acids. American Journal of Clinical Nutrition 82 1065-1073.

Keeney JT, Förster S, Sultana R, Brewer LD, Latimer CS, Cai J, Klein JB, Porter NM \& Allan Butterfield D 2013 Dietary vitamin D deficiency in rats from middle to old age leads to elevated tyrosine nitration and proteomics changes in levels of key proteins in brain: implications for low vitamin D-dependent age-related cognitive decline. Free Radical Biology \& Medicine 65 324-334. (doi:10.1016/j.freeradbiomed. 2013.07.019)

Le Ruyet P \& Le Goer P 2010 A native whey protein extract to fight sarcopenia. NutraFoods 9 33-37. (doi:10.1007/BF03223346)

Li K, Huang T, Zheng J, Wu K \& Li D 2014 Effect of marine-derived n-3 polyunsaturated fatty acids on C-reactive protein, interleukin 6 and tumor necrosis factor $\alpha$ : a meta-analysis. PLOS ONE 9 e88103. (doi:10.1371/journal.pone.0088103)

Meng Q \& Cai D 2011 Defective hypothalamic autophagy directs the central pathogenesis of obesity via the I $\kappa \mathrm{B}$ kinase $\beta(\mathrm{IKK} \beta) / \mathrm{NF}-\kappa \mathrm{B}$ pathway. Journal of Biological Chemistry 286 32324-32332. (doi:10.1074/jbc.M111.254417)

Morley JE 2010 Nutrition and the aging male. Clinics in Geriatric Medicine 26 287-299. (doi:10.1016/j.cger.2010.02.008)

Nestel PJ, Traznicky NS, Mellett NA, Wong G, De Souza DP, Tull DL, Barlow CK, Grima MT \& Meikle PJ 2014 Specific plasma lipid classes and phospholipid fatty acids indicative of dairy food consumption associate with insulin sensitivity. American Journal of Clinical Nutrition 99 46-53. (doi:10.3945/ajcn.113.071712)

Nieuwenhuizena WF, Weenena H, Rigbyb P \& Hetherington MM 2010 Older adults and patients in need of nutritional support: review of current treatment options and factors influencing nutritional intake. Clinical Nutrition 29 160-169. (doi:10.1016/j.clnu.2009.09.003)

Oliver E, McGillicuddy FC, Harford KA, Reynolds CM, Phillips CM, Ferguson JF \& Roche HM 2012 Docosahexaenoic acid attenuates macrophage-induced inflammation and improves insulin sensitivity in adipocytes-specific differential effects between LC n-3 PUFA. Journal of Nutritional Biochemistry 23 1192-1200. (doi:10.1016/j.jnutbio. 2011.06.014)

Osowska S, Duchemann T, Walrand S, Paillard A, Boirie Y, Cynober L \& Moinard C 2006 Citrulline modulates muscle protein metabolism in

Published by Bioscientifica Ltd. 
old malnourished rats. American Journal of Physiology. Endocrinology and Metabolism 291 E582-E586. (doi:10.1152/ajpendo.00398.2005)

Paddon-Jones D, Sheffield-Moore M, Zhang XJ, Volpi E, Wolf SE, Aarsland A, Ferrando AA \& Wolfe RR 2004 Amino acid ingestion improves muscle protein synthesis in the young and elderly. American Journal of Physiology. Endocrinology and Metabolism 286 E321-E328. (doi:10.1152/ajpendo.00368.2003)

Panza F, Solfrizzi V, Frisardi V, Maggi S, Sancarlo D, Adante F, D’Onofrio G, Seripa D \& Pilotto A 2011 Different models of frailty in predementia and dementia syndromes. Journal of Nutrition, Health \& Aging 15 711-719. (doi:10.1007/s12603-011-0126-1)

Paz-Filho GJ, Babikian T, Asanow R, Esposito K, Erol HK, Wong ML \& Licinio J 2008 Leptin replacement improves cognitive development. PLOS ONE 3 e3098. (doi:10.1371/journal.pone.0003098)

Pfeifer M, Begerow B, Minne HW, Suppan K, Fahrleitner-Pammer A \& Dobnig H 2009 Effects of a long-term vitamin D and calcium supplementation on falls and parameters of muscle function in community-dwelling older individuals. Osteoporosis International 20 315-322. (doi:10.1007/s00198-008-0662-7)

Philips SM, Tang JE \& Moore DR 2009 The role of milk- and soy-based protein in support of muscle synthesis and muscle protein accretion in young and elderly persons. Journal of the American College of Nutrition $\mathbf{2 8}$ 343-354. (doi:10.1080/07315724.2009.10718096)

Qi Y, Xu Z, Zhu Q, Thomas C, Kumar R, Feng H, Dostal DE, White MF, Baker KM \& Guo S 2013 Myocardial loss of IRS1 and IRS2 causes heart failure and is controlled by p38 $\alpha$ MAPK during insulin resistance. Diabetes 62 3887-3900. (doi:10.2337/db13-0095)

Rolland Y, Van Kan GA, Gillette-Guyonnet S \& Vellas B 2011 Cachexia versus sarcopenia. Current Opinion in Clinical Nutrition and Metabolic Care 14 15-21. (doi:10.1097/MCO.0b013e328340c2c2)
Schneeberger M \& Claret M 2012 Recent insights into the role of hypothalamic AMPK signaling cascade upon metabolic control. Frontiers in Neuroscience 6 185. (doi:10.3389/fnins.2012.00185)

Sohn EH, Wolden-Hanson T \& Matsumoto AM 2002 Testosterone-induced changes in arcuate nucleus cocaine-amphetamine-regulated transcript and NPY mRNA are attenuated in old compared to young male Brown Norway rats: contribution of testosterone to age-related changes in CART and NPY gene expression. Endocrinology 143 954-963. (doi:10.1210/endo.143.3.8670)

Tang JE \& Phillips SM 2009 Maximizing muscle protein anabolism: the role of protein quality. Current Opinion in Clinical Nutrition and Metabolic Care 12 66-71. (doi:10.1097/MCO.0b013e32831cef75)

Taouis M, Dagou K, Ster C, Durand G, Pinault M \& Delarue J 2002 N-3 polyunsaturated fatty acids prevent the defect of insulin receptor signaling in muscle. American Journal of Physiology. Endocrinology and Metabolism 282 E664-E671. (doi:10.1152/ajpendo. 00320.2001)

Toda C \& Diano S 2014 Mitochondrial UCP2 in the central regulation of metabolism. Best Practice \& Research. Clinical Endocrinology \& Metabolism 28 757-764. (doi:10.1016/j.beem.2014.02.006)

Volpi E, Campbell WW, Dwyer JT, Johnson MA, Jensen GL, Morley JE \& Wolfe RR 2013 Is the optimal level of protein intake for older adults greater than the recommended dietary allowance? Journals of Gerontology. Series A, Biological Sciences and Medical Sciences 68 677-681. (doi:10.1093/gerona/gls229)

Wolden-Hanson T, Marck BT \& Matsumoto AM 2004 Blunted hypothalamic neuropeptide $\mathrm{Y}$ gene expression in response to fasting, but preservation of feeding response to AgRP in aging male Brown Norway rats. American Journal of Physiology. Regulatory, Integrative and Comparative Physiology 287 138-146. (doi:10.1152/ajpregu. 00465.2003)

Received in final form 15 May 2015

Accepted 20 May 2015

Accepted Preprint published online 20 May 2015
(C) 2015 Society for Endocrinology Printed in Great Britain 